\title{
Corrigendum: Comparative genomic and phylogeographic analysis of Mycobacterium leprae
}

Marc Monot, Nadine Honoré, Thierry Garnier, Nora Zidane, Diana Sherafi, Alberto Paniz-Mondolfi, Masanori Matsuoka, G Michael Taylor, Helen D Donoghue, Abi Bouwman, Simon Mays, Claire Watson, Diana Lockwood, Ali Khamispour, Yahya Dowlati, Shen Jianping, Thomas H Rea, Lucio Vera-Cabrera, Mariane M Stefani, Sayera Banu, Murdo Macdonald, Bishwa Raj Sapkota, John S Spencer, Jérôme Thomas, Keith Harshman, Pushpendra Singh, Philippe Busso, Alexandre Gattiker, Jacques Rougemont, Patrick J Brennan \& Stewart T Cole Nat. Genet. 41, 1282-1289 (2009); published online 1 November 2009; corrected after print 5 February 2010.

In the version of this article initially published 1 November 2009, Ali Khamesipour was misspelled in the author list. The error has been corrected in the HTML and PDF versions of the article.

\section{Corrigendum: Mutations in the formin gene INF2 cause focal segmental glomerulosclerosis}

Elizabeth J Brown, Johannes S Schlöndorff, Daniel J Becker, Hiroyasu Tsukaguchi, Andrea L Uscinski, Henry N Higgs, Joel M Henderson \& Martin R Pollak

Nat. Genet. 42, 72-76 (2010); published online 20 December 2009; corrected after print 5 February 2010.

In the version of this article initially published, Stephen J. Tonna was inadvertently omitted from the author list, and the fourth author (Hiroyasu Tsukaguchi) was missing one of his affiliations. These errors have been corrected in the HTML and PDF versions of the article.

Corrigendum: Widespread and nonrandom distribution of DNA palindromes in cancer cells provides a structural platform for subsequent gene amplification

Hisashi Tanaka, Donald A Bergstrom, Meng-Chao Yao \& Stephen J Tapscott

Nat. Genet. 37, 320-327 (2005); published online 13 February 2005; corrected after print 29 March 2010

The GAPF technique identifies palindromes associated with gene amplicons in cancers; however, the initial publication over stimated the frequency of palindrome formation and the frequency of palindromes occurring in similar locations among different cancers. The performance of the modified technique is discussed in the accompanying Correspondence ${ }^{1}$.

1. Diede, S. J., Tanaka, H., Bergstrom, D.A., Yao, M.-C. \& Tapscott, S.J. Genome-wide analysis of palindrome formation. Nat. Genet. 42, 279 (2010).

\section{Erratum: Etv4 and Etv5 are required downstream of GDNF and Ret for kidney branching morphogenesis}

Benson C Lu, Cristina Cebrian, Xuan Chi, Satu Kuure, Richard Kuo, Carlton M Bates, Silvia Arber, John Hassell, Lesley MacNeil, Masato Hoshi, Sanjay Jain, Naoya Asai, Masahide Takahashi, Kai M Schmidt-Ott, Jonathan Barasch, Vivette D’Agati \& Frank Costantini Nat. Genet. 41, 1295-1302 (2009); published online 8 November 2009; corrected after print 5 February 2010.

In the version of this article initially published, the sentence under Table 1 on p. 1296 should stop after the words "and 430A arrays," and the words "or $>3$ if represented on only one array" should be removed. In addition, on p. 1298, the second parenthesis after " $T g(H o x b 7-m y r V e n u s)$ " is missing. These errors have been corrected in the HTML and PDF versions of the article. 